\title{
The characteristics of geoelectric fields at Kakioka, Kanoya, and Memambetsu inferred from voltage measurements during 2000 to 2011
}

\author{
Ikuko Fujii ${ }^{*}$, Takashi Ookawa², Shingo Nagamachi ${ }^{2}$ and Takeshi Owada ${ }^{2}$
}

\begin{abstract}
Geoelectric voltages have been continuously observed at Kakioka, Kanoya, and Memambetsu for more than 50 years. The geoelectric fields obtained at the three sites for a recent 11-year period (2000 to 2011) were examined. The fields are mainly induced by variations in the geomagnetic field at periods of less than $10^{5} \mathrm{~s}$. The instability of the observation system causes a long-term trend in the longer period band. This long-term trend can be estimated and removed using the robust Kalman filter procedure which we modified to accommodate data containing outliers. The magnetotelluric (MT) impedance at the three sites was estimated using the original geoelectric field and the geomagnetic field at periods of 6 to $10^{4} \mathrm{~s}$, and the period was extended to $10^{7} \mathrm{~s}$ at Kakioka and Memambetsu. Although the geomagnetically induced currents (GIC) at these sites may potentially be estimated using the MT impedance and geomagnetic data (if technological network information is available), the distortion effect should be corrected in order to obtain the correct regional geoelectric field. The eastward component of the geoelectric field at Kakioka shows a severe distortion effect, and the amplification factor was estimated to be approximately 10 from comparison with the $\mathrm{C}$ response at Kakioka. Conversely, the distortion effect on the eastward component of the geoelectric field at Memambetsu is almost none. The amplification factor for the northward component of the geoelectric field has not been estimated because of the lack of an independent response for comparison, although the MT response indicates a potentially large distortion at Memambetsu. Numerical modeling would be a useful tool to enable an improved estimation of this distortion.
\end{abstract}

Keywords: Geoelectric field; Kakioka; Memambetsu; Kanoya; Electromagnetic induction; Conductivity distribution; Geomagnetically induced current

\section{Background}

Geomagnetically induced currents (GIC) triggered by geomagnetic disturbances are widely recognized as potential threats to electric power networks and pipe lines at high latitudes (e.g., Bolduc 2002; Molinski 2002; Kappenman 2007). Concerns have also been raised in mid-latitude regions such as Japan (where geomagnetic disturbances are generally too weak to cause harmful GIC), given the possibility of an extreme magnetic storm event occurring (e.g., Pulkkinen et al. 2012).

There have been few published observations of GIC in Japan (e.g., Watari et al. 2009; Izutsu et al. 2011), and

\footnotetext{
* Correspondence: ifujii@mc-jma.go.jp

${ }^{1}$ Meteorological College, Japan Meteorological Agency, 7-4-81 Asahi-machi, Kashiwa, Chiba 277-0852, Japan

Full list of author information is available at the end of the article
}

little is known regarding the possible occurrence of GIC in Japan during extremely large geomagnetic disturbances. However, geoelectric fields or geoelectric voltages have commonly been observed in Japan. Most of these observations were made on a short-term basis in order to estimate the distribution of electrical conductivity in the Earth's mantle and crust.

The geoelectric voltages observed by the Kakioka Magnetic Observatory (KMO), Japan Meteorological Agency, are unique. The observatory has continuously measured the geoelectric voltage and the geomagnetic field at Kakioka (KAK, 36 $\left.13^{\prime} 56^{\prime \prime} \mathrm{N}, 140^{\circ} 11^{\prime} 11^{\prime \prime} \mathrm{E}\right)$, Kanoya (KNY, $31^{\circ} 25^{\prime} 27^{\prime \prime} \mathrm{N}, 130^{\circ} 52^{\prime} 48^{\prime \prime} \mathrm{E}$ ), and Memambetsu (MMB, $43^{\circ}$ $54^{\prime} 36^{\prime \prime} \mathrm{N}, 144^{\circ} 11^{\prime} 19^{\prime \prime} \mathrm{E}$ ) for more than 50 years (Figure 1). Similar long-term documentation of the geoelectric field on land has been recorded at Nagycenk, Hungary, since 


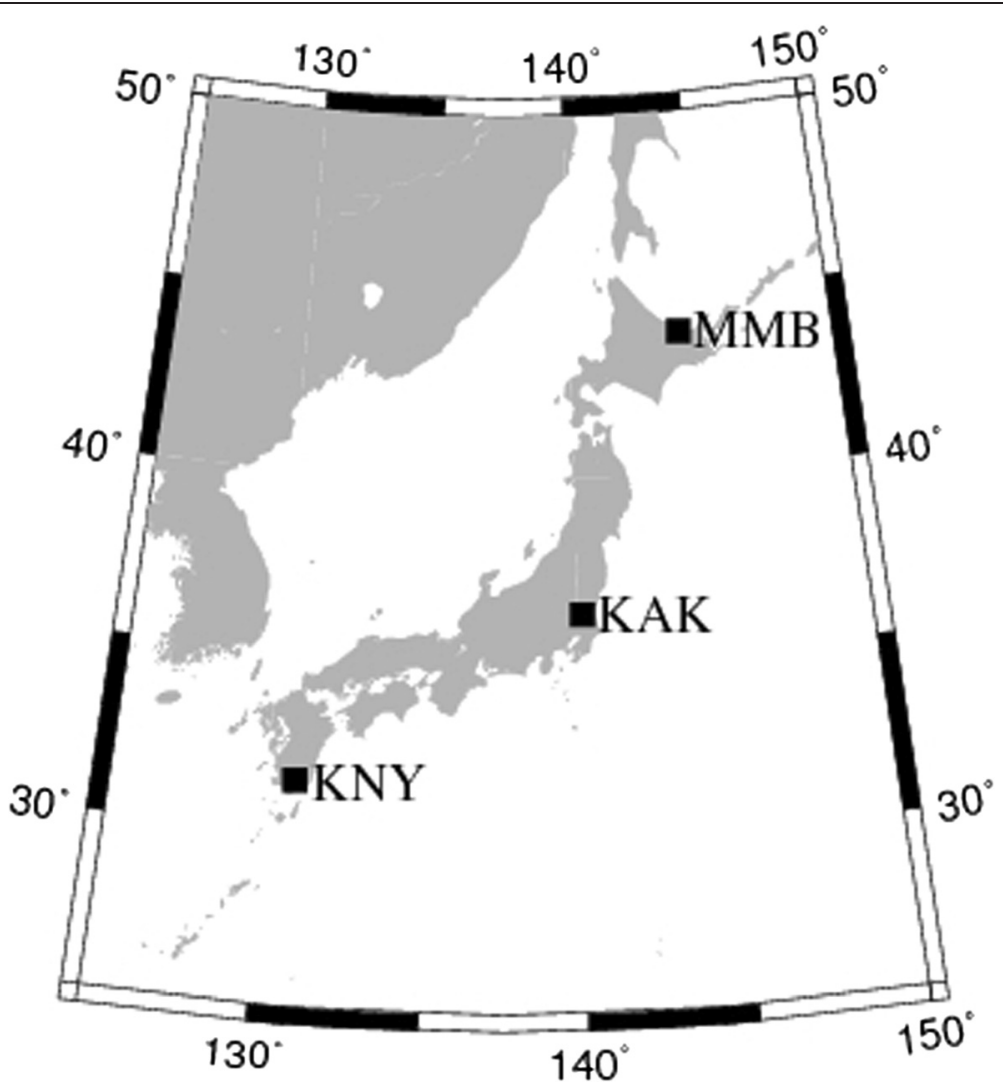

Figure 1 Locations of Kakioka, Kanoya, and Memambetsu where the geoelectric and geomagnetic field observations were conducted. KAK, Kakioka; KNY, Kanoya; MMB, Memambetsu.

1957 (e.g., Viljanen et al. 2012) and at Tucson in the 1930s (Rooney, 1949).

The geoelectric field data at KAK, KNY, and MMB were used to investigate tectonic signals and to estimate the Earth's conductivity distribution around the sites (e.g., Yokoyama 1962; Yoshimatsu 1957). If regional geoelectric fields can also be monitored from the three sites, they will be used for studies of GIC in Japan.

The GIC of a given network can be calculated from the regional geoelectric field and network data using Ohm's and Kirchhoff's laws (e.g., Lehtinen and Pirjola 1985). The network data include all resistance values in the circuits and information about the topology of the system (e.g., the number of transformers and their configuration at the substations and the connections of the transmission lines).

This study aims to analyze the geoelectric field data set at KAK, KNY, and MMB. Present and past observations are briefly described in the next section, and the characteristics of an 11-year subset of data (2000 to 2011) are described in the following two sections.

\section{Methods}

\section{Observations}

Geoelectric voltage observations started in 1932 at KAK, in 1949 at MMB, and in 1948 at KNY. These observations measure the voltage between two electrodes in the ground. The electric field is obtained by dividing the voltage by the distance between the two electrodes. Two pairs of electrodes have been installed in both the northsouth and east-west directions so that two horizontal components of the electric field are measured.

The observation details are summarized in Tables 1,2 and 3 (The Central Meteorological Observatory of Japan 1951, 1952, 1954, 1956; Japan Meteorological Agency 1963, 1964, 1970, 1971, 1975, 1984, 1989, 1991, 1992, 1994, 2003; Kakioka Magnetic Observatory 1983, 1994).

The electrode used was either a copper plate, a carbon rod, or a pod with a lead wire covered with $\mathrm{PbCl}_{2}$. Several plates or rods were sometimes used to form an electrode. The electrode locations were moved and the electrode distances changed several times, with the most recent change at KAK made in March 1988 (Japan Meteorological Agency 1989). Previously, both long-distance $(\sim 1 \mathrm{~km})$ and 
Table 1 Details of the geoelectric voltage observations at Kakioka from 1932 to the present

\begin{tabular}{|c|c|c|c|c|c|c|c|}
\hline & \multirow[t]{2}{*}{ Start date } & \multirow[t]{2}{*}{ Coordinate } & \multirow{2}{*}{$\begin{array}{l}\text { Length } \\
\text { (m) }\end{array}$} & \multicolumn{4}{|l|}{ Electrode } \\
\hline & & & & Type & Size $(m \times m)$ & Number/site & Depth (m) \\
\hline \multirow[t]{9}{*}{ N-S line } & 1 August 1932 & M & 100 & $\mathrm{Cu}$ & $0.7 \times 0.7$ & 2 & 3 \\
\hline & 1 August 1933 & M & 1,120 & $\mathrm{Cu}$ & $1 \times 1$ & 2 & \\
\hline & 5 May 1937 & M & 1,040 & $\mathrm{Cu}$ & $1 \times 1$ & 2 & \\
\hline & 10 January 1944 & M & 895 & $\mathrm{Cu}$ & $1 \times 1$ & 2 & \\
\hline & 1 August 1948 & M & 900 & C & $0.3 \times 0.05$ & 2 & \\
\hline & 1 February 1988 & G & 180 & $\mathrm{~Pb}-\mathrm{PbCl}_{2}$ & $0.2 \times 0.05$ & 1 & 4 to 1.5 \\
\hline & 1 September 1990 & G & 300 & $\mathrm{~Pb}-\mathrm{PbCl}_{2}$ & $0.2 \times 0.05$ & 1 & $\sim 3$ \\
\hline & 1 July 1991 & G & 180 & $\mathrm{~Pb}-\mathrm{PbCl}_{2}$ & $0.2 \times 0.05$ & 1 & $\sim 3$ \\
\hline & 1 September 1992 & G & 180 & $\mathrm{Cu}$ & $1 \times 0.5$ & 1 & $\sim 3$ \\
\hline \multirow[t]{5}{*}{ E-W line } & 1 August 1932 & M & 100 & $\mathrm{Cu}$ & $0.7 \times 0.7$ & 2 & 3 \\
\hline & 1 August 1933 & M & 1,500 & $\mathrm{Cu}$ & $1 \times 1$ & 2 & \\
\hline & 1 March 1983 & M & 1,200 & $\mathrm{Cu}$ & $1.4 \times 0.4(\mathrm{~W})$ & 2 & $\sim 3$ \\
\hline & 1 February 1988 & G & 190 & $\mathrm{~Pb}-\mathrm{PbCl}_{2}$ & $0.2 \times 0.05$ & 1 & 4 to 1.5 \\
\hline & 1 January 1993 & G & 190 & $\mathrm{Cu}$ & $1 \times 0.5$ & 1 & $\sim 3$ \\
\hline
\end{tabular}

The terms 'N-S line' and 'E-W line' denote the north-south and east-west measurement lines along which the geoelectric voltages are observed, respectively. $\mathrm{M}$ and $\mathrm{G}$ in the 'Coordinate' column denote the geomagnetic and geographic coordinate systems, respectively, which are used for electrode alignment. The electrode type is represented by either $\mathrm{Cu}$ (copper plate), $\mathrm{C}$ (carbon rod) or $\mathrm{Pb}-\mathrm{PbCl}_{2}$ (pod with a $\mathrm{Pb}$ wire covered with $\mathrm{PbCl}$ ). The number per site for each electrode states how many plates or rods are combined to form an electrode at the end of the measurement line. ' $W$ ' in the 'Size' column indicates that the listed electrode size is for the electrode at the western end, which was replaced in 1983.

short-distance $(\sim 300 \mathrm{~m})$ observations were undertaken; however, the long-distance observations ceased in 1988 because population pressures around the three sites rendered large-scale observations difficult. The short-distance observations have been undertaken since 1988 at all three observatories.

The sampling rate has increased with updates in the data acquisition system. Until the 1980s, only hourly values of the electric field obtained through analog observations were available. The observation of values every minute began at the three sites in 1987, associated with the installation of digital observation and recording systems. The observation of values every $0.1 \mathrm{~s}$ (decisecond) and every second were added in 1996 to 1997 and 2000 to 2001, respectively. (The decisecond observation started earlier.) The data acquisition system was updated in 2010, and a further minor change was undertaken in 2012.

It has become apparent that the decisecond and 1-s values recorded prior to 2012 were affected by the digital filters of the observation systems. They were low-pass filtered with a $3.3 \mathrm{~s}$ cut-off period until the end of 2010 . The cut-off period of the low-pass filter was changed to

Table 2 Details of the geoelectric voltage observations at Kanoya from 1948 to the present

\begin{tabular}{|c|c|c|c|c|c|c|c|}
\hline & \multirow[t]{2}{*}{ Start date } & \multirow[t]{2}{*}{ Coordinate } & \multirow[t]{2}{*}{ Length $(\mathrm{m})$} & \multicolumn{4}{|c|}{ Electrode } \\
\hline & & & & Type & Size $(m \times m)$ & Number/site & Depth (m) \\
\hline \multirow[t]{3}{*}{$\mathrm{N}$-S line } & 1 January 1948 & G & 2,800 & $\mathrm{C}$ & $0.3 \times 0.05$ & 2 & 3 \\
\hline & 28 March 1961 & G & 1,009 & C & $0.3 \times 0.05$ & 2 & $\sim 3$ \\
\hline & 1 July 1974 & G & 200 & C & $0.7 \times 0.08$ & 2 & $\sim 3$ \\
\hline \multirow[t]{9}{*}{ E-W line } & 1 January 1948 & G & 1,650 & $\mathrm{C}$ & $0.3 \times 0.05$ & 2 & 3 \\
\hline & 9 July 1954 & G & 1,450 & C & $0.3 \times 0.05$ & 2 & 3 \\
\hline & 29 September 1954 & G & 1,650 & C & $0.3 \times 0.05$ & 2 & 3 \\
\hline & 15 November 1954 & G & 1,450 & C & $0.3 \times 0.05$ & 2 & 3 \\
\hline & 30 November 1954 & G & 1,650 & C & $0.3 \times 0.05$ & 2 & 3 \\
\hline & 10 December 1954 & G & 1,450 & C & $0.3 \times 0.05$ & 2 & 3 \\
\hline & 17 December 1954 & G & 1,650 & C & $0.3 \times 0.05$ & 2 & 3 \\
\hline & 28 March 1961 & G & 1,000 & C & $0.3 \times 0.05$ & 2 & $\sim 3$ \\
\hline & 1 July 1974 & G & 200 & C & $0.7 \times 0.08$ & 2 & 3 \\
\hline
\end{tabular}


Table 3 Details of the geoelectric voltage observations at Memambetsu from 1948 to the present

\begin{tabular}{|c|c|c|c|c|c|c|c|}
\hline & \multirow[t]{2}{*}{ Start date } & \multirow[t]{2}{*}{ Coordinate } & \multirow[t]{2}{*}{ Length $(\mathrm{m})$} & \multicolumn{4}{|c|}{ Electrode } \\
\hline & & & & Type & Size $(m \times m)$ & Number/site & Depth (m) \\
\hline \multirow[t]{5}{*}{ N-S line } & 1 January 1950 & G & 195 & C & $0.5 \times 0.05$ & 4 & 2.5 \\
\hline & 1 January 1956 & G & 900 & C & $0.5 \times 0.05$ & 1 to 2 & $\sim 3$ \\
\hline & 1 July 1961 & G & 400 & C & $0.3 \times 0.03$ & 2 & $\sim 3$ \\
\hline & 1 January 1970 & G & 130 & C & $0.3 \times 0.03$ & 2 & $\sim 3$ \\
\hline & 1 December 2001 & G & 300 & $\mathrm{Cu}$ & $0.6 \times 0.36$ & 1 & $\sim 3$ \\
\hline \multirow[t]{5}{*}{$\mathrm{E}-\mathrm{W}$ line } & 1 January 1950 & G & 160 & C & $0.5 \times 0.05$ & 4 & 2.5 \\
\hline & 1 January 1956 & G & 700 & C & $0.5 \times 0.05$ & 1 to 2 & $\sim 3$ \\
\hline & 1 July 1961 & G & 350 & C & $0.3 \times 0.03$ & 2 & $\sim 3$ \\
\hline & 1 January 1970 & G & 150 & $C$ & $0.3 \times 0.03$ & 2 & $\sim 3$ \\
\hline & 1 December 2001 & G & 300 & $\mathrm{Cu}$ & $0.6 \times 0.36$ & 1 & $\sim 3$ \\
\hline
\end{tabular}

Abbreviations and symbols are the same as in Table 1.

$0.1 \mathrm{~s}$ in 2011. For the decisecond data, a high-pass filter with a $150 \mathrm{~s}$ cut-off period was also applied until the end of 2011. As a result, the decisecond values were severely distorted in both amplitude and phase. Filter coefficients for the decisecond values were measured every month at periods of 1 to $150 \mathrm{~s}$ and are available if required.

The three vector components of the geomagnetic field were measured a few hundred meters away from the geoelectric field observation lines at the three observatories. Part of the geoelectric and geomagnetic field data set from the KMO is available online (http://www.kakioka-jma. go.jp/metadata), and the data are updated every month.

\section{Geoelectric field data for an 11-year time period}

We selected an 11-year subset of the geoelectric data set at KAK, KNY, and MMB, from 1 January 2000 to 28 February 2011, with which to investigate the characteristics of the geoelectric field. This time period was chosen because (1) several technical staff who were in charge of the geoelectric observations during that period still work for the KMO, (2) the observation systems are well documented and field notes are systematically written, and (3) the observations were unaffected by the 2011 off the Pacific coast of Tohoku Earthquake on 11 March 2011.

Figure 2 shows the 11-year subset of the geoelectric field data at the three sites. Hereafter, a geographic coordinate system is used. The largest amplitude geoelectric field fluctuations are observed during geomagnetic storms, which indicates that the geomagnetically induced field dominates the data.

The baselines of the geoelectric fields show instabilities, especially at KAK and MMB. The electric field at KAK often shows a distinct drift after a rainfall event (Ookawa et al. 1995). These instabilities suggest that the conditions around the electrodes are affected by meteorological conditions. The $E_{\mathrm{y}}$ (eastward) component of the geoelectric field at KNY shows clear annual variations which indicate that the observation system is dependent on the surrounding air temperature to some extent.

An example of higher frequency fluctuations of the geoelectric fields at the three sites is shown in Figure 3. In each case, the 12-hour subset has values recorded every 1 min starting from 12:00 (noon) on 24 October 2003. This allows the data to be compared with the geoelectric field recorded at Nagycenk during the same period, as shown in Viljanen et al. (2012). Several similarities are seen in the geoelectric variations at the three sites. However, there are striking differences in the amplitudes of the fluctuations. In particular, $E_{\mathrm{y}}$ at KAK exhibits extremely large fluctuations. Fluctuations in the $E_{\mathrm{y}}$ component are generally larger than those associated with the $E_{\mathrm{x}}$ (northward) component at both KAK and KNY. On the other hand, the two components of the geoelectric field at Nagycenk have similar amplitudes and the $E_{\mathrm{y}}$ component shows some similarities to the geoelectric field at the three sites.

Figure 4 shows the power spectrum of the geoelectric field and the coherence between the geoelectric field and the geomagnetic field at KAK. Spectra in the shorter period band were computed using 1-s values from 7 November 2004, while those in the longer period band were computed using hourly values from 22 October 2004 to 24 March 2005. The two horizontal components of the electric field are induced by variations in the geomagnetic field at periods of up to $2 \times 10^{5} \mathrm{~s}$ because the geoelectric field and the geomagnetic field are coherent with each other within this period. Coherence at periods of less than $10^{2} \mathrm{~s}$, known as "the dead band", is low, probably because of artificial noise. However, coherence increases when it is computed using data collected during a magnetic storm (Figure 5).

The situation seems to be different at periods of longer than $10^{4} \mathrm{~s}$. Clear line spectra from solar quiet variations (Sq) and tides are seen in the power spectra at periods 


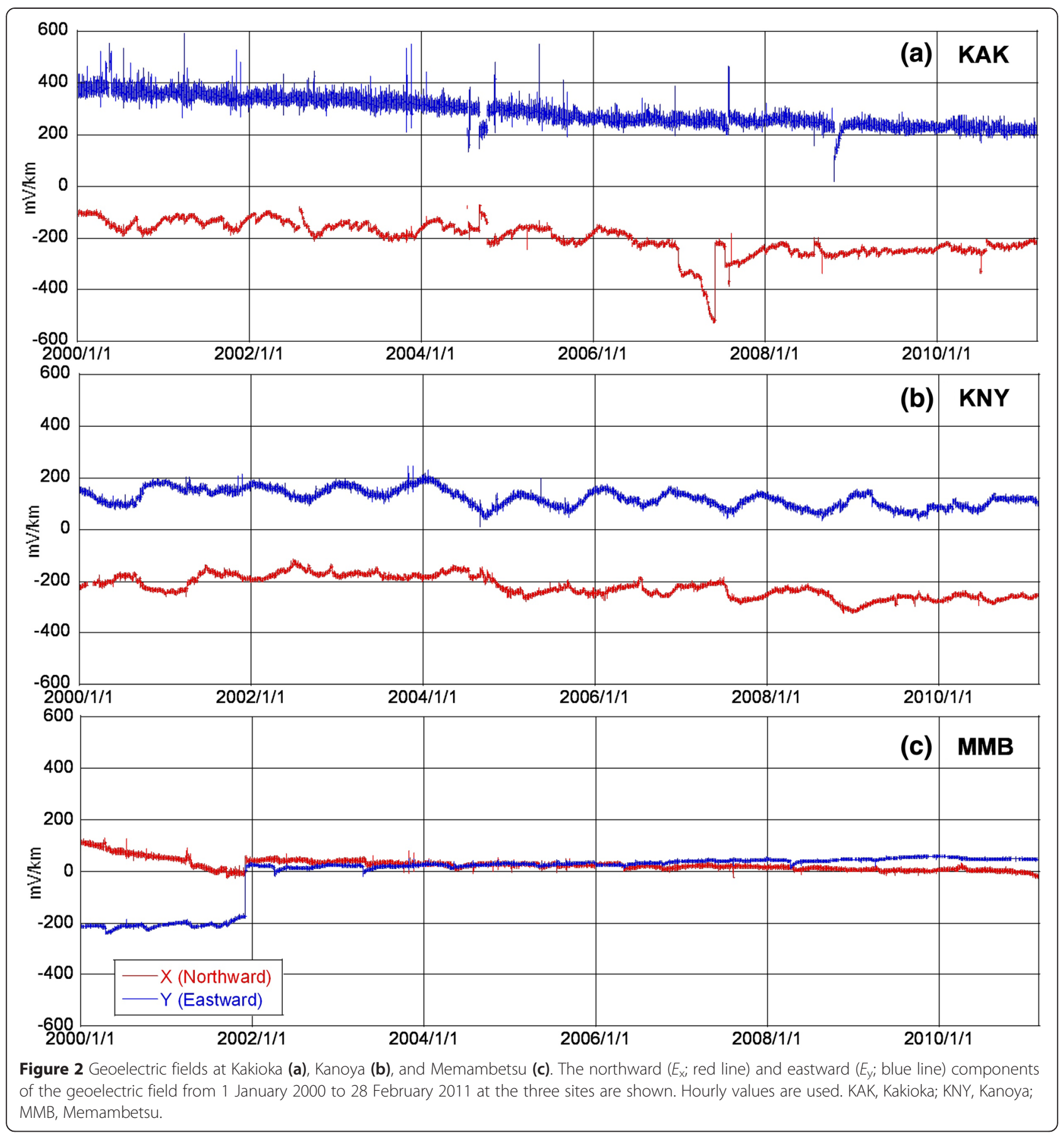

of $10^{4}$ to $10^{5} \mathrm{~s}$, as expected, while the power spectra continue to increase with increasing period length, which is not the case for a typical geomagnetically induced electric field (Luther et al. 1991). Since the coherence between the geoelectric field and the geomagnetic field decreases quickly at periods of longer than $10^{5} \mathrm{~s}$, the geoelectric field variation is dominated by a factor other than the geomagnetic field variation. The baseline instabilities shown in Figure 2 may be a plausible alternative causal factor.
Decomposition of the geoelectric field

Time series model of the geoelectric field

We assume that the geoelectric field at KAK, KNY, and MMB consists of three components, as follows:

$$
\mathbf{E}(t)=\mathbf{G}(t)+\mathbf{L}(t)+\mathbf{T}(t)+\mathbf{W}(t)
$$

where $\mathbf{E}(t)=\left(E_{\mathrm{x}} E_{\mathrm{y}}\right)^{\mathrm{T}}$ is a horizontal vector of the geoelectric field at time $t$. The term $\mathbf{G}(t)$ denotes the 

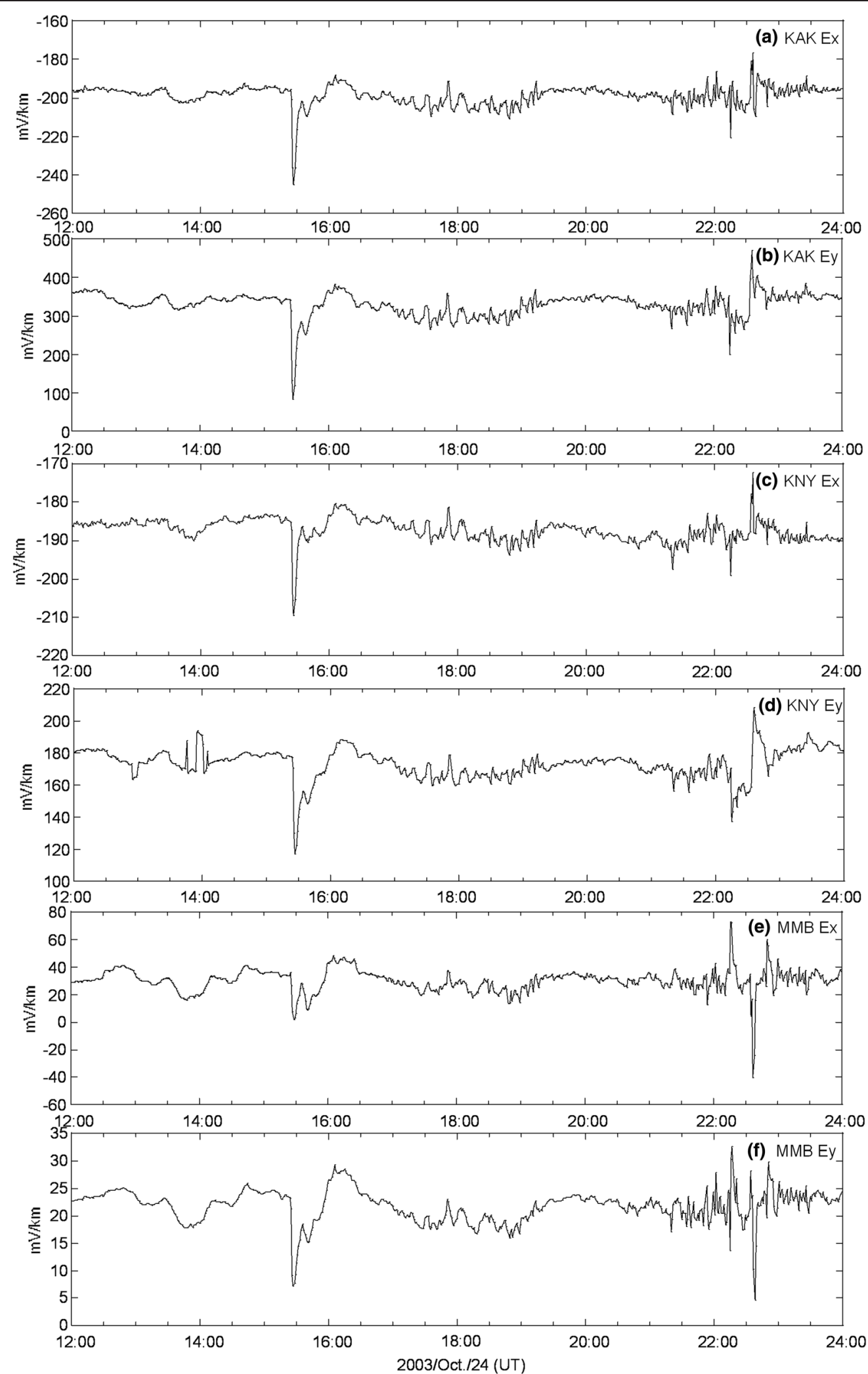

Figure 3 Geoelectric fields at Kakioka (a, b), Kanoya (c, d), and Memambetsu (e, f). The northward $\left(E_{x} ; \mathbf{a}, \mathbf{c}, \mathbf{e}\right)$ and eastward $\left(E_{y} ; \mathbf{b}, \mathbf{d}, \mathbf{f}\right)$ components of the geoelectric field from 12:00 to 24:00 on 24 October 2003 at the three sites are shown. One-minute values are used. KAK, Kakioka; KNY, Kanoya; MMB, Memambetsu. 

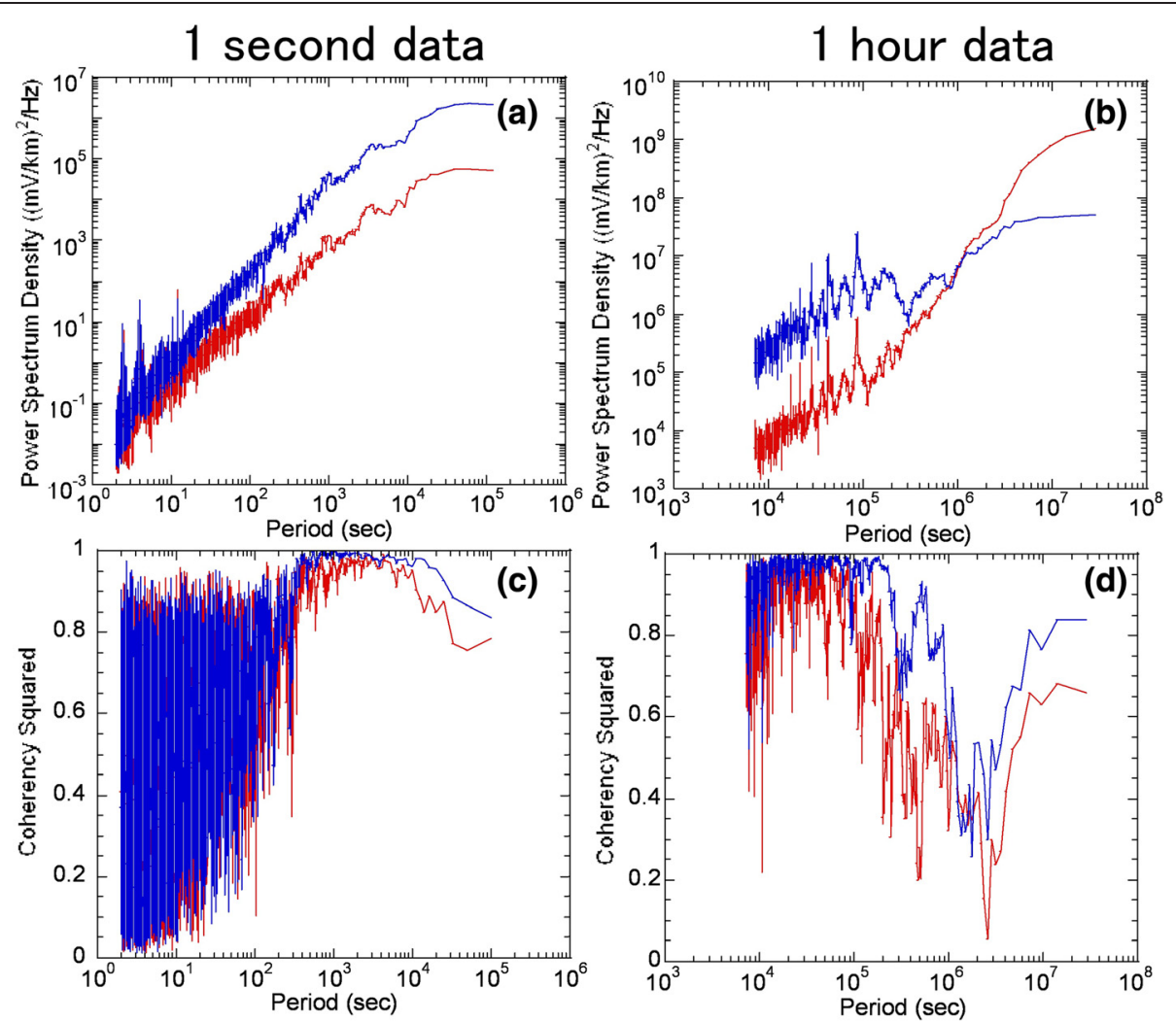

Figure 4 Power spectra and coherence of the geoelectric field at Kakioka. Power spectra of the geoelectric field ( $\mathbf{a}, \mathbf{b})$ and coherence between the geoelectric and geomagnetic fields $(\mathbf{c}, \mathbf{d})$ are shown. Spectra at shorter period bands were computed using 1-s values on 7 November 2004 $(\mathbf{a}, \mathbf{c})$, while those at longer period bands were computed using hourly values from 22 October 2004 to 24 March 2005 (b, d). The spectra related to $E_{\mathrm{x}}$ (red line) and $E_{\mathrm{y}}$ (blue line) are shown.

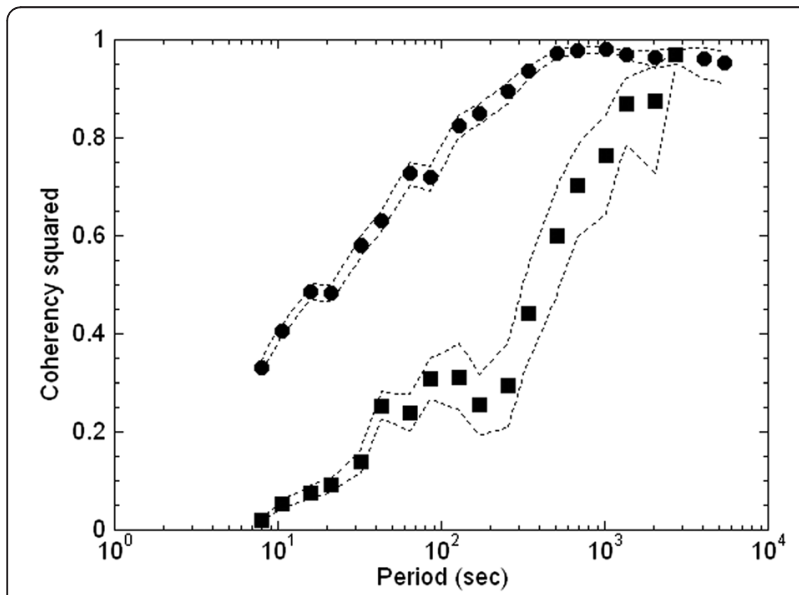

Figure 5 Comparison of the coherences during a disturbed time and a slightly disturbed time at Kakioka. The coherences of the geoelectric and geomagnetic fields during a magnetic storm (circles) and during a slightly disturbed time (squares) for Kakioka are shown. Dotted lines show the errors in coherence. geoelectric field induced by the geomagnetic field variation, and $\mathbf{W}(t)$ represents the random noise component.

The term $\mathbf{L}(t)$ denotes the electric field generated by small-scale anomalies in the electrical conductivity distribution in the ground and is known as the distortion (see details in Chave and Jones, 2012). This term depends on the location and the baseline length and therefore is strongly local.

The term $\mathbf{T}(t)$ represents a long-term trend seen in Figures 2 and 4 . This trend component is probably caused by instability in the observation system and therefore is unrelated to geomagnetic field variations. The trend component is dominant during periods of longer than a few days.

We describe the analytical methods used to estimate the three components of Equation 1 in the following three subsections.

\section{Long-period system noise}

A trend-estimating procedure using the Kalman filter technique, as developed by Fujii and Kanda (2008), was adapted to estimate $\mathbf{T}(t)$ from $\mathbf{E}(t)$. Our primarily modification to this method was to add a robust procedure 
with which to accommodate the geoelectric data, with its anomalous spikes and sudden trend changes.

The procedure proposed by Fujii and Kanda (2008) splits $E_{i}(t)(i=\mathrm{x}, \mathrm{y})$, a vector component of the electric field, into four parts:

$$
E_{i}(t)=T(t)+S(t)+R(t)+w(t)
$$

where $T(t), S(t), R(t)$, and $w(t)$ denote the trend, a periodic part, a part correlated with reference data, and random noise, respectively. $T(t)$ corresponds to a vector component of $\mathbf{T}(t)$ in Equation (1), while the sum $S+R$ corresponds to a vector component of $\mathbf{G}+\mathbf{L}$ in Equation (1).

The first procedure to be added was the ability of the analytical method to accommodate sudden changes such as a baseline shift or drift due to rainfall. We make the trend component accommodate these sudden changes at a preset time. The trend component in Fujii and Kanda (2008) is assumed to be smooth in time $(t)$ and to follow:

$$
T(t)-2 T(t-1)+T(t-2)=u(t)
$$

where $u(t)$ is a random number drawn from a Gaussian distribution with a mean of 0 and a variance of $\tau^{2}$. In this study, the trend component is permitted to ignore Equation 3 at a given time $t=t_{a}$ when the trend changes rapidly. An arbitrarily large number is set as an initial value of $u\left(t_{a}\right)$, and an estimate of $u\left(t_{a}\right)$ is excluded from the evaluation of $\tau^{2}$.

The second procedure we have added to the method of Fujii and Kanda (2008) is used to remove outliers such as spikes in the data. A datum is regarded as an outlier and is treated as a data gap if it satisfies:

$$
w(t)>k \sigma_{\mathrm{MAD}}
$$

where $\sigma_{\mathrm{MAD}}$ is the median absolute deviation and $k$ is the amplifier. We typically set $k$ as 7 to 10 in order to detect obvious outliers. This outlier detection procedure is iteratively applied and the decomposition of Equation 2 is recalculated after Equation 4, until no outliers are detected or three iterations have been completed, whichever occurs first.

We also made three additional minor changes. The smoothing procedure of the Kalman filter (Katayama 1983) was added as an option to the final part of the analysis procedure in order to obtain more stable estimates. Future values can also be predicted as an option. In addition, an oscillation effect caused by the initial values was weakened by using improved estimates of the initial values.

These additions significantly increased the number of computation steps, and we therefore accelerated the computations involving huge sparse matrixes to reduce the computational processing time.

\section{Geomagnetically induced fields}

Magnetotellurics (e.g., Cagniard 1953) (hereafter MT) makes use of the relationship between $\mathbf{G}$ and the geomagnetic field variation $\mathbf{B}=\left(B_{\mathrm{x}} B_{\mathrm{y}}\right)^{\mathrm{T}}$ in the frequency domain as follows:

$$
\left(\begin{array}{c}
G_{\mathrm{x}}(\omega) \\
G_{\mathrm{y}}(\omega)
\end{array}\right)=\frac{1}{\mu_{0}}\left(\begin{array}{ll}
Z_{\mathrm{xx}}(\omega) & Z_{\mathrm{xy}}(\omega) \\
Z_{\mathrm{yx}}(\omega) & Z_{\mathrm{yy}}(\omega)
\end{array}\right)\left(\begin{array}{c}
B_{\mathrm{x}}(\omega) \\
B_{\mathrm{y}}(\omega)
\end{array}\right)
$$

where $\omega$ denotes an angular frequency and $Z_{i j}(i, j=\mathrm{x}, \mathrm{y})$ is a transfer function of the geoelectric field $E_{i}$ to the geomagnetic field $B_{j}$ whose dimension is an impedance; $\mu_{0}$ is the vacuum permeability. The impedance tensor $\mathbf{Z}$ is defined as:

$$
\mathbf{Z}(\omega)=\left(\begin{array}{ll}
Z_{\mathrm{xx}}(\omega) & Z_{\mathrm{xy}}(\omega) \\
Z_{\mathrm{yx}}(\omega) & Z_{\mathrm{yy}}(\omega)
\end{array}\right)
$$

MT studies reveal that the observed electric field is always affected by the distortion effect. The distortion $\mathbf{L}$ couples with $\mathbf{G}$ as follows:

$$
\mathbf{L}(\omega)+\mathbf{G}(\omega)=\mathbf{D G}(\omega) \equiv \mathbf{G}^{\prime}(\omega)
$$

where $\mathbf{D}$ is a distortion tensor, which is known to be static (i.e., independent of $\omega$ ) in many cases. The separation of $\mathbf{G}$ from $\mathbf{L}$ is a debated issue in MT but is possible with some assumptions. As a result, if one estimates an impedance tensor by using observed geoelectric and geomagnetic fields, it is expressed as:

$$
\mathbf{G}^{\prime}(\omega)=\frac{1}{\mu_{0}} \mathbf{Z}^{\prime}(\omega) \mathbf{B}(\omega)
$$

where $\mathbf{Z}^{\prime}(\omega)$ is an impedance tensor including the distortion effect. Note that GIC is driven by $\mathbf{G}^{\prime}$ not $\mathbf{G}$. However, in general, the distortion effect is weakened when the geoelectric field is considered over a longer spatial scale, and $\mathbf{G}$ approximately drives the GIC in such cases.

$\mathbf{Z}^{\prime}(\omega)$ and $\mathbf{Z}(\omega)$ are constant over time unless the geological conditions or the source field morphology change. Therefore, once the impedances are obtained, the geomagnetically induced field can be predicted from the geomagnetic field, using the impedance as a filter in the time domain:

$$
G_{\mathrm{x}}^{\prime}(t)=\sum_{i=-\infty}^{\infty}\left\{Z_{\mathrm{xx}}^{\prime}(i) B_{\mathrm{x}}(t+i)+Z_{\mathrm{xy}}^{\prime}(i) B_{\mathrm{y}}(t+i)\right\}
$$

where $i$ denotes a time lag or lead. Using both past and future time steps improves the accuracy of $G_{\mathrm{x}}{ }^{\prime}$ because the data are discretely sampled (Egbert 1992). Equation 9 is obtained by applying the inverse fast Fourier transform (FFT) to Equation 8 over all FFT frequencies.

Computation of $\mathbf{Z}^{\prime}(\omega)$ was done by using the bounded influence remote-reference processing (BIRRP) program developed by Chave and Thomson (2004). The value of 
$\mathbf{Z}^{\prime}(\omega)$ at periods shorter than $10^{4} \mathrm{~s}$ was obtained by simply applying BIRRP to the observed geoelectric and geomagnetic fields, based on the high coherence between them. On the other hand, the corrected electric field $\mathbf{E}(t)-\mathbf{T}(t)$ is used at periods longer than $10^{4} \mathrm{~s}$ to enhance the signal-to-noise ratio. In addition, the Sq signal is removed before the spectral analysis by fitting sinusoids with a 24-hour period and related harmonics to the geoelectric and geomagnetic fields.

The BIRRP can correct the filtering effect of the measuring systems. Prior to 2012, measured filter coefficients corresponding to the time period of the data were used to correct the decisecond values of the geoelectric and geomagnetic fields. However, no filter correction was applied to the 1-s values because no measured coefficients are available for the geoelectric field. For the geomagnetic field, the filter coefficients for the fluxgate magnetometers are available (Owada et al. 1998; Yamazaki and Mishima 2013). However, the original geomagnetic northward and eastward fields were not traceable after transforming the data into horizontal force and declination with a tentative baseline value, which was not fully documented. Since the system effect will be seen at shorter period bands, $\mathbf{Z}^{\prime}(\omega)$ of the 1-s values were used only at periods longer than $100 \mathrm{~s}$ for KAK, $80 \mathrm{~s}$ for KNY, and $30 \mathrm{~s}$ for MMB where $\mathbf{Z}^{\prime}(\omega)$ of the 1 -s values overlaps with that of the decisecond values.

\section{Distortion by small-scale geological structures}

An estimation of the distortion effect $\mathbf{D}$ may be used to extract the regional field $\mathbf{G}$ from the observed electric field $\mathbf{G}^{\prime}$. The regional field reflects a resolvable large-scale structure of the conductivity distribution in the region, while the distortion is caused by irresolvable small-scale structures. The distortion is highly local and would be weakened if the GIC was estimated on the scale of an electrical power line (10 to $100 \mathrm{~km}$ ).

The distorted impedance tensor $\mathbf{Z}^{\prime}$ is generally written as:

$$
\begin{aligned}
\mathbf{Z}^{\prime}= & \left(\begin{array}{cc}
\cos \theta & -\sin \theta \\
\sin \theta & \cos \theta
\end{array}\right)\left(\begin{array}{cc}
\cos \alpha_{\mathrm{x}} & \sin \alpha_{\mathrm{y}} \\
-\sin \alpha_{\mathrm{x}} & \cos \alpha_{\mathrm{y}}
\end{array}\right) \\
& \times\left(\begin{array}{ll}
s_{\mathrm{x}} Z_{\mathrm{xx}} & s_{\mathrm{x}} Z_{\mathrm{xy}} \\
s_{\mathrm{y}} Z_{\mathrm{yx}} & s_{\mathrm{y}} Z_{\mathrm{yy}}
\end{array}\right)\left(\begin{array}{cc}
\cos \theta & \sin \theta \\
-\sin \theta & \cos \theta
\end{array}\right)
\end{aligned}
$$

where $\theta$ is the rotation angle between the measured coordinates and the strike of regional geological structure, $\alpha_{\mathrm{x}}$ and $\alpha_{\mathrm{y}}$ are the regional electric field's rotation angles by the distortion, and $s_{\mathrm{x}}$ and $s_{\mathrm{y}}$ are the amplification factors of the distortion (Booker 2014). $\theta, \alpha_{\mathrm{x}}$, and $\alpha_{\mathrm{y}}$ can be obtained from estimates of $\mathbf{Z}^{\prime}$ via the phase tensor (Caldwell et al. 2004).

Given that $s_{\mathrm{x}}$ and $s_{\mathrm{y}}$ are indeterminable, the estimation of the amplification factors $s_{\mathrm{x}}$ and $s_{\mathrm{y}}$ requires additional conditions. For instance, if the regional structure is twodimensional, a decomposition method is used, as proposed by Groom and Bailey (1989). If there are several observation sites in the area, a separation of the local and regional components can be applied in the case of a three-dimensional regional structure. However, the regional structures at KAK, KNY, and MMB are unknown, and they are separated from each other by about 500 $\mathrm{km}$. Therefore, we used another approach to infer $s_{\mathrm{y}}$. Our approach is valid only for $E_{\mathrm{y}}$, so estimation of $s_{\mathrm{x}}$ is a topic for future work.

The inducing geomagnetic field variation $\mathbf{B}$ is assumed to be located far from the observation site and to be a plane wave in MT studies. This assumption has been successful for periods of less than $10^{4} \mathrm{~s}$, while the inducing geomagnetic field generated by an equatorial ring current in the magnetosphere becomes dominant at periods of longer than 5 days (e.g., Fujii and Schultz 2002). The ring current source generates $E_{\mathrm{y}}, B_{\mathrm{x}}$, and $B_{\mathrm{z}}$ in a onedimensional earth so that the elements of the impedance tensors, except $Z_{\mathrm{yx}}$, become insignificant and can be regarded as equivalent to zero in a longer period band.

The transfer function often used for periods of longer than 5 days is the $C$ response (Schmucker 1970), which is computed from the geomagnetic field:

$$
C(\omega)=-\frac{R_{e} \tan \Theta}{2} \frac{B_{r}(\omega)}{B_{\Theta}(\omega)}
$$

where $R_{e}$ and $\Theta$ denote the Earth's radius and co-latitude, respectively. $B_{r}$ and $B_{\Theta}$ are the radial and co-latitude components, respectively, of the geomagnetic field in the spherical coordinate system in which the pole is the geomagnetic pole. If the Earth is one-dimensional and the inducing source is the equatorial ring current, $\mathrm{Z}_{\phi \Theta}$ and $C$ can be related as follows:

$$
Z_{\phi \Theta}(\omega)=i \omega C(\omega)
$$

where $\phi$ is the longitude (e.g., Schultz and Larsen 1987). The impedance tensor in the local geographic coordinate system is obtained from Equation 12 by using the declination $d$ as follows:

$$
\begin{aligned}
Z= & \left(\begin{array}{cc}
\cos d & -\sin d \\
\sin d & \cos d
\end{array}\right)\left(\begin{array}{cc}
0 & 0 \\
-i \omega C & 0
\end{array}\right) \\
& \times\left(\begin{array}{cc}
\cos d & \sin d \\
-\sin d & \cos d
\end{array}\right)
\end{aligned}
$$

Since the $C$ response is supposed to be distortion free, a comparison between $Z_{\mathrm{yx}}$ from Equation 13 and the observed $Z_{y x}^{\prime}$ leads to an estimation of $s_{\mathrm{y}}$ (Egbert et al. 1992; Schultz et al. 1993). Equation 13 generates all four tensor components, but we only use $Z_{\mathrm{yx}}$ because it is the primary component. The dimensionality beneath the 
three sites is unknown; however, this comparison will provide a first-order approximation of $s_{\mathrm{y}}$.

\section{Results}

\section{Long-period system noise}

The original hourly geoelectric field data show intensive trend variations (Figure 2). In particular, the northward component $E_{\mathrm{x}}$ at KAK suffers from frequent baseline shifts and rapid drifts as well as slow variations. We have attempted to estimate the long-term system noise of $E_{\mathrm{x}}$ at KAK in order to recover the geomagnetically induced field. The robust Kalman filter procedure described in the previous section was applied to a 4-year segment from 2002 to 2005 for the hourly mean data set of $E_{\mathrm{x}}$ at KAK. The trend term $T(t)$ was used in this study after separating the data into the four components of Equation 2.

The fitting of the sinusoidal variation due to $\mathrm{Sq}$ and its harmonics did not work for the hourly data at KAK as it is difficult to detect small baseline shifts in the data with the intensive Sq variations. Therefore, we took four steps to estimate the trend from a given component of the geomagnetic field $E_{i}(t)$. Firstly, an initial list of the times of large $(>10 \mathrm{mV} / \mathrm{km})$ baseline shifts was made by visual inspection. The robust Kalman filter was then applied to $E_{i}(t)$, referring to the list of baseline shift start times in order to estimate the trend $T_{0}(t)$. The subscript 0 refers to the initial estimate. Secondly, the sinusoidal variation in the periods of Sq and its harmonics, $S_{0}(t)$, were fitted to the residual $E_{i}(t)-T_{0}(t)$. Thirdly, the residual $E_{i}(t)-$ $S_{0}(t)$ was checked visually and the list of the baseline shift start times was updated by including small $(<10$ $\mathrm{mV} / \mathrm{km}$ ) baseline shifts. Finally, the robust Kalman filter was applied to $E_{i}(t)-S_{0}(t)$ to obtain $T(t)$, referring to the updated list of baseline shift start times.

It became evident that the trend estimate cannot follow a few data points at the start part of a very rapid drift. This generates a small number of large residuals which dominate the first iteration of outlier detection. We temporarily treated these data points as data gaps in order to allow the outlier detection process to detect less obvious outliers when the Kalman filter was applied to the data.

We used three vector components of the geomagnetic field from the same site as the reference data and selected 30 data points from both the past and future. The periodicity variance for the periodic component was set to $10^{-3}$.

The trend variance $\tau^{2}$ in our computation ranged from $10^{-4}$ to $10^{-6}$, allowing us to search its optimum value. A larger $\mathrm{t}^{2}$ leads to a more flexible trend component which results in smaller residuals. The estimated trend contains variations over periods longer than $\sim 5$ days for $\tau^{2}=10^{-5}$, while it contains variations over periods longer than $\sim 2$ days for $\tau^{2}=10^{-4}$. The variance $\tau^{2}=10^{-4}$ was chosen because the long-term system noise becomes dominant over periods of longer than a few days.

Figure 6 shows the trend of $E_{\mathrm{x}}$ at KAK, as estimated by the robust Kalman filter. The starting time list of 84 baseline shifts was input and the amplitudes of the shifts were estimated using the robust Kalman filter. The residual of $E_{\mathrm{x}}$ was calculated by subtracting the trend from the $E_{\mathrm{x}}$ data (Figure 6) and shows no intensive long-term variations. The baseline shifts of greater than several $\mathrm{mV} / \mathrm{km}$ were detected and removed from the trend. The coherence between the geoelectric field and the geomagnetic field suggests that the residual is mostly induced by the geomagnetic field variations, and that the signalto-noise ratio is largely recovered by removing the trend (Figure 7).

The trend components were estimated in the same manner for $E_{\mathrm{x}}$ and $E_{\mathrm{y}}$ at MMB. A total of 19 and 17 baseline shifts were detected in $E_{\mathrm{x}}$ and $E_{\mathrm{y}}$ at $\mathrm{MMB}$, respectively. For $E_{\mathrm{y}}$ at KAK, the second to the fourth steps described in this section were not applied because the residual from the trend obtained at the first step enhanced the coherence between the geoelectric field and the geomagnetic field up to 0.8 or more. Fifteen baseline shifts were detected for $E_{\mathrm{y}}$ at KAK.

\section{MT impedance}

The MT impedances at KAK, KNY, and MMB were estimated at periods from 6 to $10^{4} \mathrm{~s}$, which are relevant to GIC (Figure 8). The impedance is shown in the form of the apparent resistivity $\rho_{i j}$ and the phase $\theta_{i j}$ as follows:

$$
\rho_{i j}=\frac{\left|Z_{i j}\right|^{2}}{\omega \mu}, \theta_{i j}=\arg \left(Z_{i j}\right)
$$

where $i$ and $j$ are either of $\mathrm{x}$ and $\mathrm{y}$.

The data used to compute the impedance were decisecond values for periods of less than $10^{2} \mathrm{~s}, 1$-s values for periods of $10^{2}$ to $10^{3} \mathrm{~s}$, and 1-min values for periods of $10^{3}$ to $10^{4} \mathrm{~s}$. The time periods used were a 4-day segment starting on 7 November 2004 for KAK and KNY and a 3day segment starting on 29 October 2003 for MMB. Both time periods contain intensive magnetic storms.

The MT impedances at the three sites differ from each other, suggesting that the conductivity distributions beneath the three sites also differ. The conductivity distribution at KNY appears to be the simplest of the three sites; it is one-dimensional in its shallower part and shows multidimensionality in its deeper part. For KAK, $\rho_{\mathrm{yx}}$ is always the largest among the four impedances and shows an unrealistically high value, even at a period of $10^{4} \mathrm{~s}$. This can be expected from the large amplitude of $E_{\mathrm{y}}$ shown in Figures 2 and 3 . This distortion probably generates a large static shift in the apparent resistivity. In addition, $\rho_{\mathrm{yx}}$ and $\rho_{\mathrm{xy}}$ at KAK are clearly split in all periods, which indicates 

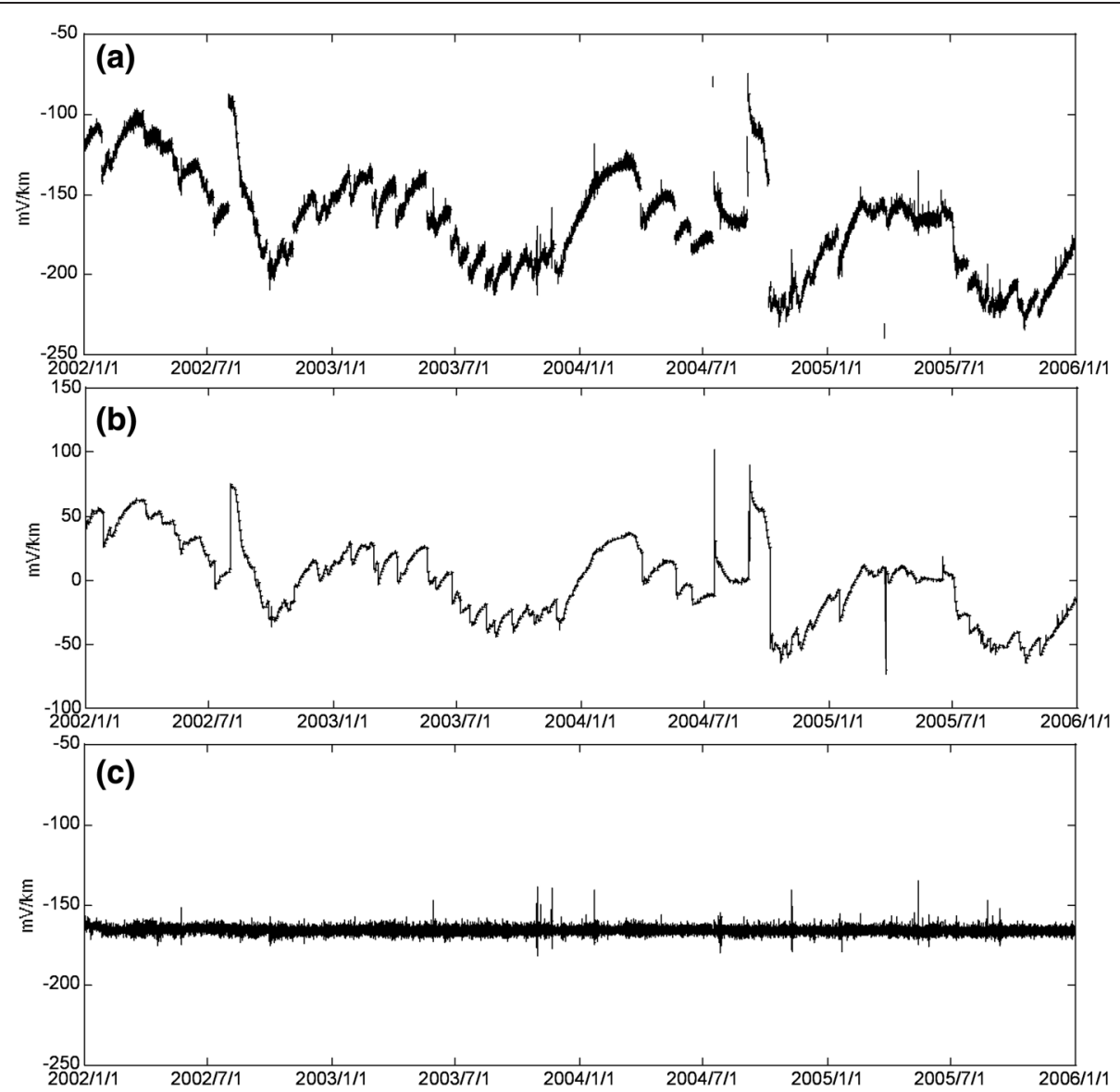

Figure 6 The northward geoelectric field from 1 January 2002 to 31 December 2005 at Kakioka. (a) Observed hourly values, (b) the trend component estimated by the robust Kalman filter procedure, and (c) the residual of the geomagnetic field when the trend is subtracted.

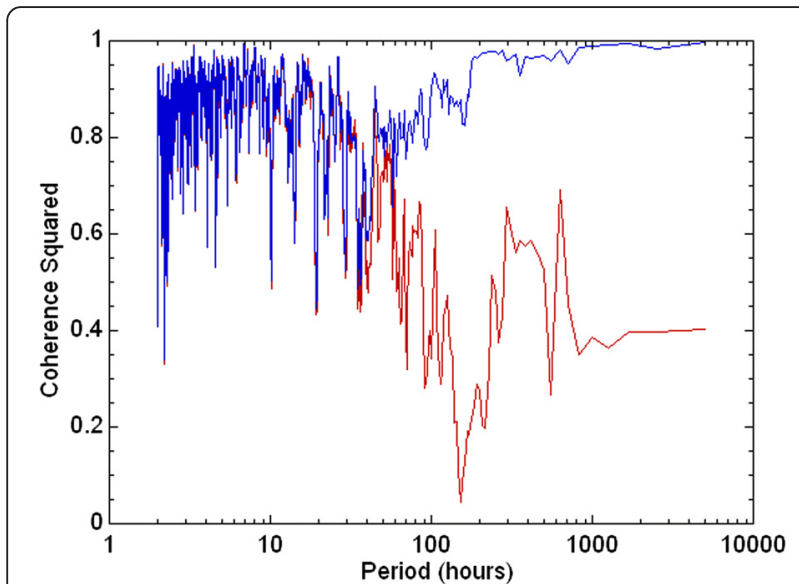

Figure 7 Comparison of coherences with (red line) and without (blue line) the geomagnetic field trend. Coherences between the geomagnetic field and the geoelectric field are shown. that a conductivity boundary is located near KAK. The impedance at MMB also shows multidimensionality, such that the off-diagonal elements of the impedance tensor split. $\rho_{\mathrm{xy}}$ has a larger amplitude than $\rho_{\mathrm{yx}}$, as expected from the large amplitude of $E_{\mathrm{x}}$ shown in Figures 2 and 3. The impedance at MMB indicates that the contribution of $B_{\mathrm{y}}$ should not be neglected in order to predict the geoelectric field at MMB.

\section{Distortion}

The MT impedances at periods of $10^{4}$ to $10^{6} \mathrm{~s}$ were computed at KAK and MMB to compare with the $C$ response at periods of longer than 5 days and to examine the distortion effect of $E_{\mathrm{y}}$. This is one of the longest period ranges over which the MT response was estimated. The data used were $E_{\mathrm{x}}$ and $E_{\mathrm{y}}$ with the trend removed, as shown in Figure 6, and the geomagnetic field $B_{\mathrm{x}}$ and $B_{\mathrm{y}}$. The least squares fit of the sinusoids over 24 hours and their harmonics were removed from both the geoelectric and geomagnetic fields in order to avoid the influence of the sharp spectrum peaks associated with 


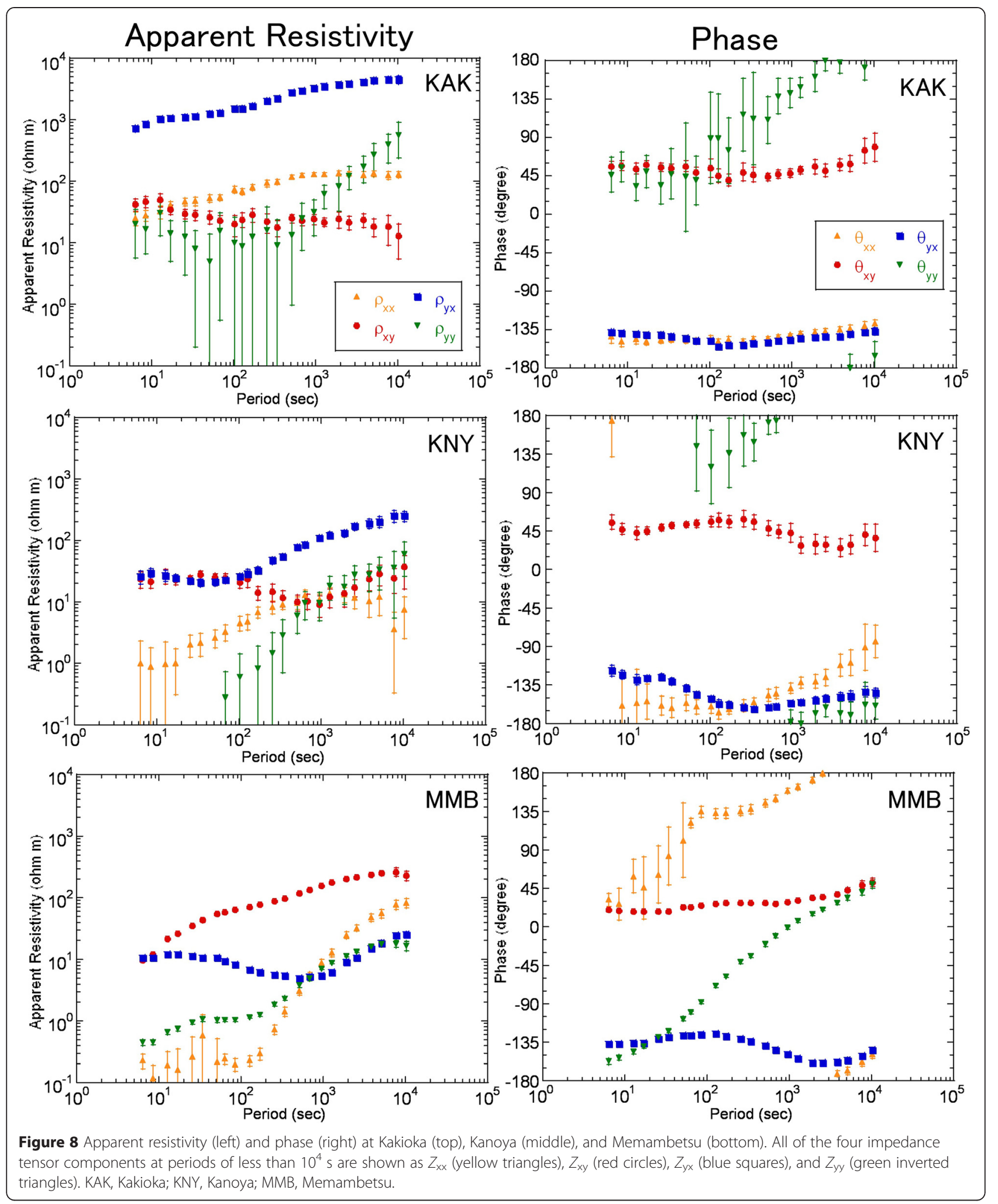

Sq and tides. The $\mathrm{C}$ response was obtained by Fujii and Schultz (2002) and was converted into impedance following Equation 13.
Figures 9 and 10 compare the observed and converted apparent resistivity and phase at KAK and MMB, respectively. The impedances which are related to $B_{\mathrm{x}}$ are 

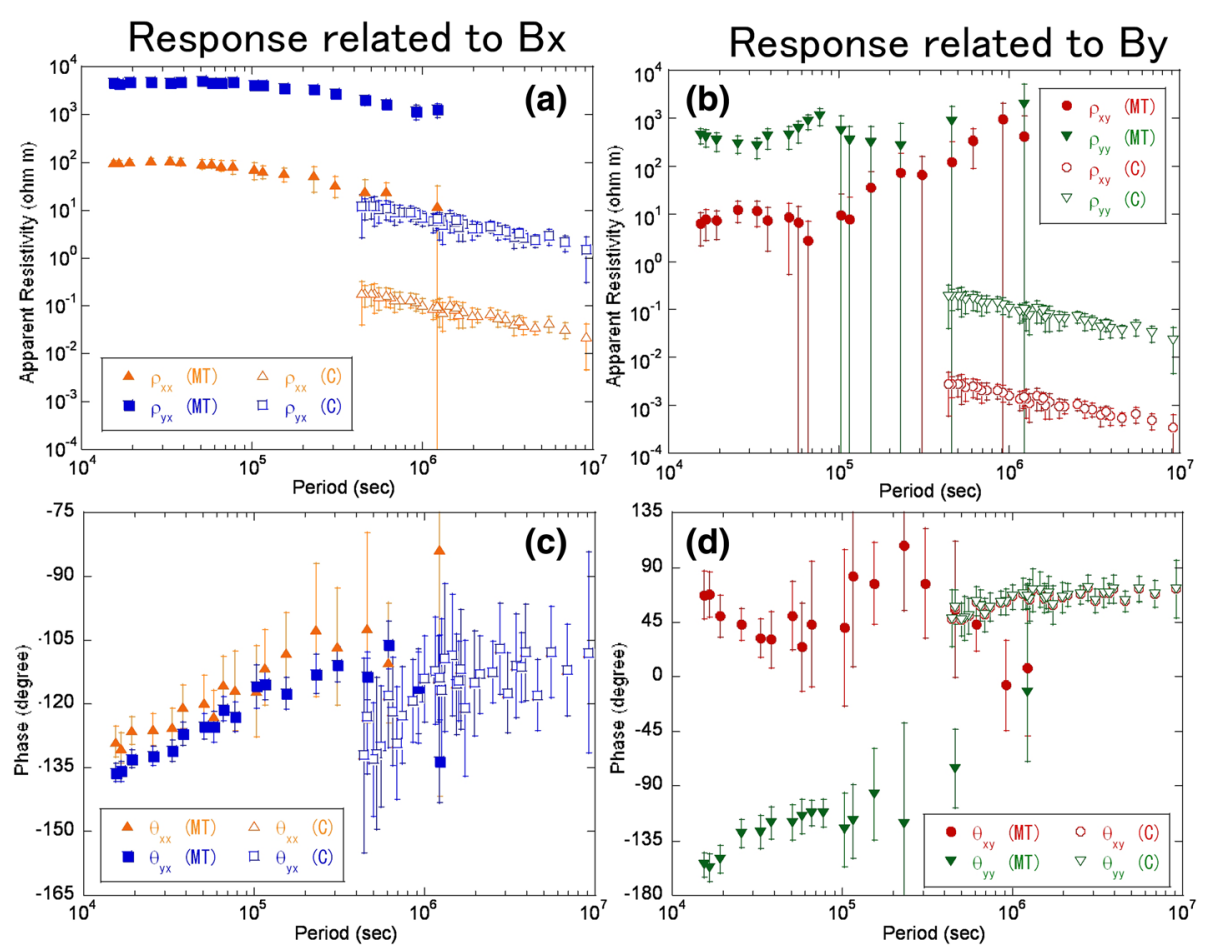

Figure $\mathbf{9}$ Comparison of the observed and converted magnetotelluric impedances at Kakioka. The apparent resistivity (a, b) and phase (c, d) estimated from the geoelectric and geomagnetic fields (solid symbols), and as estimated from the $C$ response (open symbols) are shown. The color and shape of the symbols are as in Figure 8. $Z_{x x}$ and $Z_{y x}$ are on the left panels $(\mathbf{a}, \mathbf{c})$ and $Z_{x y}$ and $Z_{y y}$ are on the right panels $(\mathbf{b}, \mathbf{d})$. MT, magnetotellurics.

stable, while others become unstable at periods of longer than $10^{5} \mathrm{~s}$. This is because the ring current becomes the dominant inducing source at longer periods; therefore, $B_{\mathrm{y}}$ gradually vanishes as the period increases. The impedance $Z_{\mathrm{yx}}$ at both KAK and MMB may include errors in the longest period band because the phase $\theta_{\mathrm{yx}}$ quickly drops in that band. This drop, if it is an error, is probably due to remaining small baseline shifts. We use $\rho_{\mathrm{yx}}$ at periods of less than $7 \times 10^{5} \mathrm{~s}$ for KAK and at periods of shorter than $3 \times 10^{5} \mathrm{~s}$ for MMB.

The observed and converted $\rho_{\mathrm{yx}}$ at KAK are parallel, and the observed $\rho_{\mathrm{yx}}$ is approximately 100 times larger than the converted $\rho_{\mathrm{yx}}$ (Figure 9). The observed and converted phases of $\theta_{\mathrm{yx}}$ are close, with a difference between them of about $15^{\circ}$. If the discrepancy between the observed and converted impedances can be assumed as a static shift, a rough estimate of $s_{\mathrm{y}}$ is 10 , which suggests a severe distortion. If $s_{\mathrm{y}}$ is set as $10, \rho_{\mathrm{yy}}$ becomes 100 times smaller with the distortion corrected and will overlap with the converted value.

In the case of $\mathrm{MMB}$, the observed and converted $\rho_{\mathrm{yx}}$ will connect smoothly if the observed $\rho_{\mathrm{yx}}$ at periods of longer than $3 \times 10^{5} \mathrm{~s}$ is neglected. This tendency is also seen in $\rho_{\text {yy. }}$. The differences between the observed and converted $\rho_{\mathrm{yx}}$ are similar to, or smaller than, those at
KAK. Therefore, $s_{\mathrm{y}}$ can be estimated as 1 , which indicates a moderate level of distortion.

\section{Discussion}

The geoelectric fields at KAK, KNY, and MMB are highly correlated to the geomagnetic field variations at periods of less than $10^{5} \mathrm{~s}$. This shows a possibility to utilize the geoelectric fields at the three sites for estimating GIC. A longer distance between the electrodes will amplify the signal, and the improvement of the electrodes will stabilize the data.

Note that the geoelectric field data at KAK, KNY, and MMB must be processed to recover precisely the geomagnetically induced signal. The signals are affected by the observation system for both shorter (< approximately $100 \mathrm{~s}$ ) and longer (> approximately 2 days) period bands. Particularly for data obtained prior to 2012, the system's filter effect is severe for shorter periods. The MT impedances for periods shorter than $10^{4} \mathrm{~s}$ are computed by employing the decisecond, 1-s, and 1-min values of the geoelectric and geomagnetic fields, as described in the previous section. To obtain Figure 8, we carefully checked if the impedances from different sampling data overlapped with each other or whether they smoothly connected across all frequencies. We also compared the impedances 

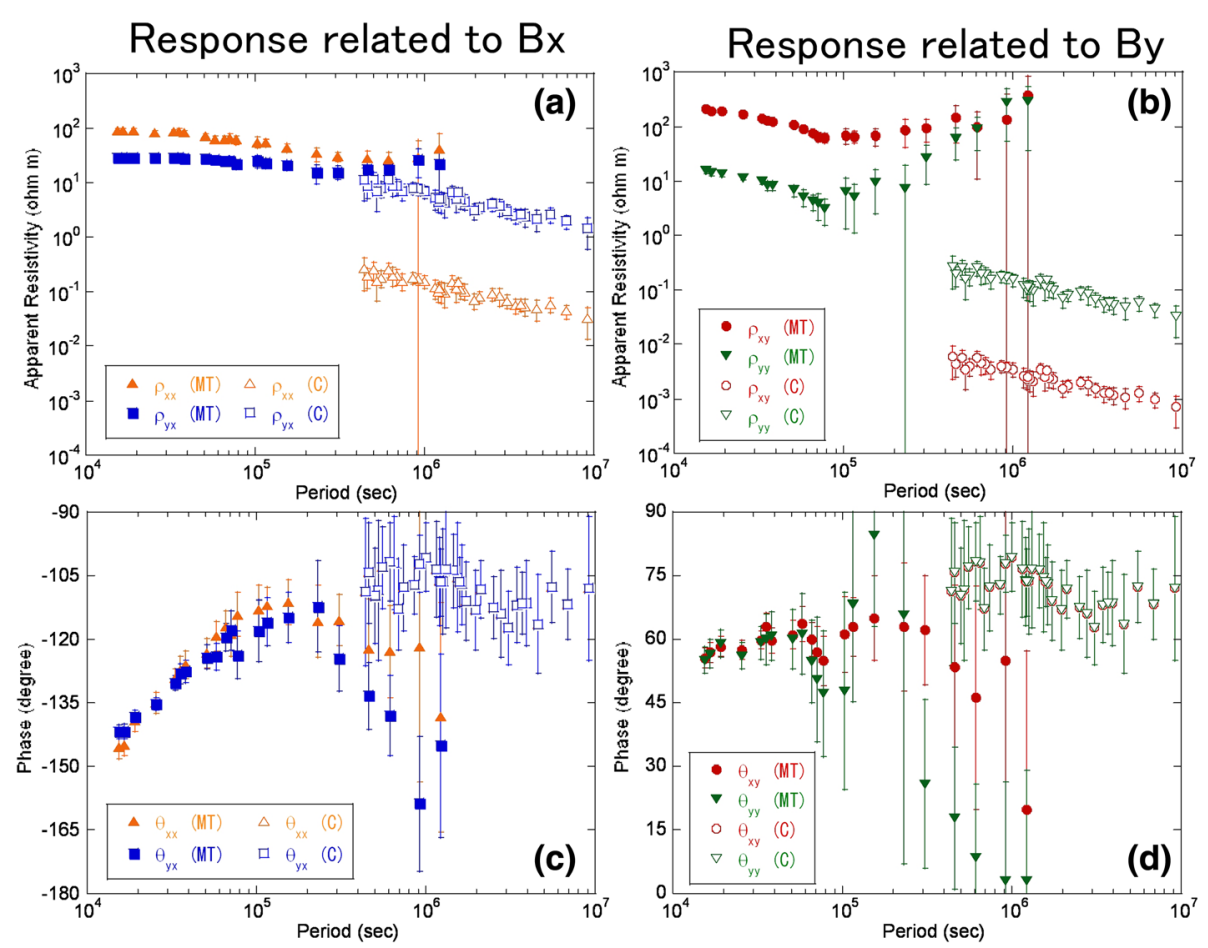

Figure 10 Same as Figure 9 but at the MMB observatory. MT, magnetotellurics.

from different data segments to check if they are mutually consistent. As a result, the signal for periods shorter than $6 \mathrm{~s}$ in the decisecond values and that for periods shorter than 30 to $100 \mathrm{~s}$, depending on the observation site, in the 1 -s values could not be recovered. We suspect that the system filter coefficient is imperfect for the decisecond values and the sampling timing might affect the phase of the 1-s values. Care must be taken if the decisecond and 1-s values of the geoelectric data are used in the time domain.

For longer period bands, the trend estimation might affect the signal estimation, because the trend is much stronger than the signal for that period band (Figure 6). We checked the influence of $\tau^{2}$ on the MT impedance. $Z_{\mathrm{yx}}$ at KAK after the trend at $\mathrm{\tau}^{2}=10^{-4}$ or $\mathrm{\tau}^{2}=10^{-5}$ is removed from $E_{\mathrm{y}}$, compared with the equivalent value for no trend correction (Figure 11). The trend correction works to reduce the confidence limit (the error bars) for periods shorter than $7 \times 10^{5} \mathrm{~s}$. Therefore, trend removal does not distort the signal. On the other hand, the signal is not detected without trend removal for periods longer than $7 \times 10^{5} \mathrm{~s}$. Benchmarks of the MT impedance for these longest periods would retain their smoothness over all frequencies and physically reasonable distributions.

In addition to the signal processing, a precise estimation of the distortion effect is necessary for a realistic monitoring of the geoelectric field and thus, indirectly, GIC.
The large amplitude of $E_{\mathrm{y}}$ at KAK, as seen at Figures 2 and 3, has been previously noted. For instance, Yanagihara and Yokouchi (1965) attributed the unusually large amplitude of $E_{\mathrm{y}}$ at KAK to the exposure of granite base rocks, rather than the surrounding sediments near Kakioka. This heterogeneous geological structure would generate a large distortion effect. Yanagihara and Yokouchi (1965) estimated an amplification factor for $E_{\mathrm{y}}$ at KAK of 6.7, using a simple two-dimensional model which includes a conductive sediment and a resistive granite. Their amplification factor is close to the $s_{\mathrm{y}}$ value indicated in Figure 9. Granites and gabbros occur in the Tsukuba mountains, located several kilometers west of the observatory, and metamorphic rocks and granites are exposed at the surface on hillsides next to the observatory (Miyazaki et al. 1996). The sediment thickness in the Kakioka area was estimated as approximately $30 \mathrm{~m}$ by electric prospecting (Mori et al. 1978), which is relatively shallow, because Kakioka is located near the margin of the Kanto plain.

The large $\rho_{\mathrm{yx}}$ value at KAK persists over an extremely wide period range $\left(6\right.$ to $\left.6 \times 10^{5} \mathrm{~s}\right)$, and the inductive scale length (Schmucker 1970, 1973) ranges between values on the order of 1 to $10^{3} \mathrm{~km}$, with the conductivity on the order of 10 to $10^{3} \mathrm{~S} / \mathrm{m}$. The distortion effect may be caused by more than one geological structure and might not be represented by the same amplification factor across the whole period range. For instance, KAK is 

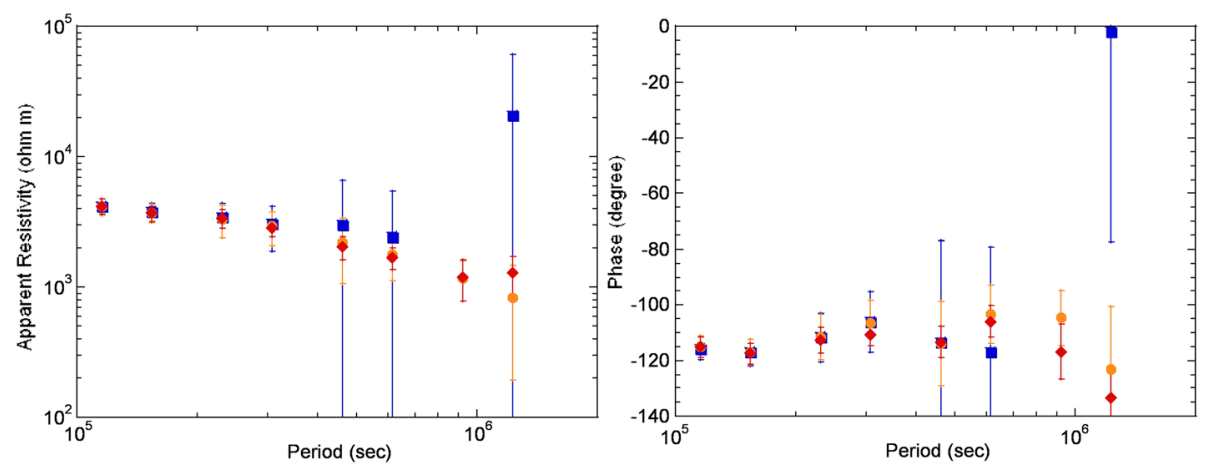

Figure 11 Comparison of $Z_{y x}$ at KAK with and without trend correction. The trends at $\tau^{2}=10^{-4}$ (red diamonds) and $\mathrm{T}^{2}=10^{-5}$ (orange circles) are removed from $E_{y}$, while no trend correction is applied to $E_{y}$ (blue squares).

located about $30 \mathrm{~km}$ inland from the Pacific coast and the conductive seawater plays a role in induction at periods of longer than about 10 to $10^{2} \mathrm{~s}$.

Figures 9 and 10 shows that $\rho_{\mathrm{xy}}$ can have amplitudes of as large as $10^{2} \Omega \mathrm{m}$ in the longest period band. If it is unreasonable to assume that the Earth is so resistive down to the lower mantle, a distortion in $E_{\mathrm{x}}$ should be considered. In particular, Figure 10 indicates that the distortion effect of $E_{\mathrm{x}}$ is stronger than that of $E_{\mathrm{y}}$ at MMB.

Numerical modeling would help our understanding of the distortion effect of $E_{\mathrm{x}}$ and $E_{\mathrm{y}}$. For instance, Püthe et al. (2014) estimated D at KAK, KNY, and MMB by comparing the observed and computed geoelectric fields at the three sites, and they reported a qualitative success. Their numerical model consists of a three-dimensional surface layer (reflecting distributions of sea water, sediments, and rocks) with one-dimensional layers underneath. Their horizontal grid size is $1 \times 1^{\circ}$, which is large compared with the local geological setting at the three sites. Smaller scale modeling was attempted by Fujita et al. (2014), but their $12.5 \times 12.5 \mathrm{~km}$ grid size still underestimates the distortion at KAK, and qualitatively explains $\rho_{\mathrm{yx}}$ and $\rho_{\mathrm{xy}}$ at MMB by invoking the coast effect. This suggests that local, three-dimensional modeling is necessary to quantify the distortion effects on the impedances at KAK, KNY, and MMB.

\section{Conclusions}

The geoelectric fields observed at KAK, KNY, and MMB for a recent 11-year period (2000 to 2011) were examined. The characteristics of the geoelectric fields at the three sites are summarized as follows:

(1) The fields are mainly induced by variations in the geomagnetic field at periods of less than $10^{5} \mathrm{~s}$.

(2) The instability of the observation system seems to cause a long-term trend in the longer period band. This long-term trend can be estimated and removed using the robust Kalman filter procedure which we modified to accommodate data containing outliers.

(3) The MT impedance at the three sites was estimated using the geoelectric field and the geomagnetic field at periods of 6 to $10^{4} \mathrm{~s}$, and the period was extended to $\sim 10^{7} \mathrm{~s}$ at KAK and MMB.

(4) The MT impedance at KAK shows a severe distortion effect, especially on $Z_{\mathrm{yx}}$, and the amplification factor for $E_{\mathrm{y}}$ at KAK was estimated to be approximately 10 from comparison with the $C$ response at KAK. The amplification factor for $E_{\mathrm{y}}$ was about 1 at MMB. The amplification factor for $E_{\mathrm{x}}$ has not been estimated, although the MT response indicates a potentially large distortion in $Z_{\mathrm{xy}}$ at MMB.

\section{Abbreviations}

GIC: geomagnetically induced current; KAK: Kakioka (observation site name); KMO: Kakioka Magnetic Observatory (organization name); KNY: Kanoya; MMB: Memambetsu; MT: magnetotellurics.

\section{Competing interests}

The authors declare that they have no competing interests.

\section{Authors' contributions}

IF designed the study, carried out the data processing and the spectral analysis, and drafted the manuscript. TOo and TOw provided technical information on the geoelectrical voltage observations. SN summarized the history of the observation details. TOo, TOW, and SN collected the geoelectrical voltage observations at KMO. All authors read and approved the final manuscript.

Authors' information

Most of this work was undertaken as a research activity of KMO when IF worked for KMO.

\section{Acknowledgements}

We are sincerely grateful to all the staff of $\mathrm{KMO}$ for keeping the geoelectric voltage observations going for more than 80 years. We also thank Takeshi Toya and Kenji Morinaga for informative advices on the geoelectric voltage observation at KMO. We also thank two anonymous reviewers for their constructive comments which improved the manuscript. 


\section{Author details}

${ }^{1}$ Meteorological College, Japan Meteorological Agency, 7-4-81 Asahi-machi, Kashiwa, Chiba 277-0852, Japan. ${ }^{2}$ Kakioka Magnetic Observatory, Japan Meteorological Agency, 595 Kakioka, Ishioka, Ibaraki 315-0115, Japan.

\section{Received: 7 November 2014 Accepted: 23 April 2015} Published online: 08 May 2015

\section{References}

Bolduc L (2002) GIC observations and studies in the Hydro-Québec power system. J Atmos Sol-Terr Phys 64(16):1793-1802

Booker JR (2014) The magnetotelluric phase tensor: a critical review. Surv Geophys 35(1):7-40

Cagniard L (1953) Basic theory of the magnetotelluric method of geophysical prospecting. Geophysics 18:605-635

Caldwell TG, Bibby HM, Brown C (2004) The magnetotelluric phase tensor. Geophys J Int 158(2):457-469

Chave A, Jones A (eds) (2012) The magnetotelluric method: theory and practice. Cambridge Univ Press, Cambridge

Chave AD, Thomson DJ (2004) Bounded influence magnetotelluric response function estimation. Geophys J Inter 157(3):988-1006

Egbert GD (1992) Noncausality of the discrete-time magnetotelluric impulse response. Geophys 57(10):1354-1358

Egbert G, Booker J, Schultz A (1992) Very long period magnetotellurics at Tucson Observatory: estimation of impedances. J Geophys Res 97(B11):15113-15128

Fujii I, Kanda W (2008) New procedures to decompose geomagnetic field variations and application to volcanic activities. Geophys J Inter 175:400-414, doi:10.1111/j.1365-246X.2008.03870.x

Fujii I, Schultz A (2002) The three-dimensional electromagnetic response of the Earth to ring current and auroral oval excitation. Geophys J Inter 151:689709

Fujita S, Fujii I, Tominaga H (2014) A hazard map for the geomagnetically induced current disaster in Japan, SGEPSS Fall Meeting Abstr. (Available at http:// www.sgepss.org/sgepss/sookai/136/html/program/pdf/R010/R010-06.pdf. Accessed on 13 March 2015)

Groom RW, Bailey RC (1989) Decomposition of magnetotelluric impedance tensors in the presence of local three-dimensional galvanic distortion. J Geophys Res 94(B2):1913-1925

Izutsu J, Nagata S, Wada T, Shimizu M, Ohta K (2011) A long-period observation of Neutral current at an extra-high voltage transformer in Chubu region. IEEJ 131(9):678-683 (in Japanese with English abstract)

Japan Meteorological Agency (1963) Report of the Kakioka Magnetic Observatory geoelectricity Kanoya 1950-1956. Japan Meteorological Agency, Tokyo

Japan Meteorological Agency (1964) Report of the Kakioka Magnetic Observatory geoelectricity Memambetsu 1950-1956. Japan Meteorological Agency, Tokyo

Japan Meteorological Agency (1970) Report of the Kakioka Magnetic Observatory geoelectricity Kakioka, Memambetsu, Kanoya 1961. Japan Meteorological Agency, Tokyo

Japan Meteorological Agency (1971) Report of the Kakioka Magnetic Observatory geoelectricity Kakioka, Memambetsu, Kanoya 1970. Japan Meteorological Agency, Tokyo

Japan Meteorological Agency (1975) Report of the Kakioka Magnetic Observatory geoelectricity Kakioka, Memambetsu, Kanoya 1974. Japan Meteorological Agency, Tokyo

Japan Meteorological Agency (1984) Report of the Kakioka Magnetic Observatory geoelectricity Kakioka, Memambetsu, Kanoya 1983. Japan Meteorological Agency, Tokyo

Japan Meteorological Agency (1989) Report of the Kakioka Magnetic Observatory geoelectricity Kakioka, Memambetsu, Kanoya 1988. Japan Meteorological Agency, Tokyo

Japan Meteorological Agency (1991) Report of the Kakioka Magnetic Observatory geoelectricity Kakioka, Memambetsu, Kanoya 1990. Japan Meteorological Agency, Tokyo

Japan Meteorological Agency (1992) Report of the Kakioka Magnetic Observatory geoelectricity Kakioka, Memambetsu, Kanoya 1991. Japan Meteorological Agency, Tokyo

Japan Meteorological Agency (1994) Report of the Kakioka Magnetic Observatory geoelectricity Kakioka, Memambetsu, Kanoya 1993. Japan Meteorological Agency, Tokyo
Japan Meteorological Agency (2003) Report of the Kakioka Magnetic Observatory geomagnetism and geoelectricity Kakioka, Memambetsu, Kanoya, Chichijima 2001. Japan Meteorological Agency, Tokyo

Kakioka Magnetic Observatory (1983) 100-year history of the geomagnetic field observation in Japan. Kakioka Magnetic Observatory, Ibaraki, in Japanese

Kakioka Magnetic Observatory (1994) Guide for the geoelectric field observation, the atmospheric electric field observation, and the DI flux magnetometer observation. Gijyutuhoukoku 34(suppl):1-122, in Japanese

Kappenman JG (2007) Geomagnetic disturbances and impacts upon power system operation. In: Grigsby LL (ed) The Electric Power Engineering Handbook, 2nd edn. CRC Press/IEEE Press, Boca Raton, pp 16-1-16-22 Katayama T (1983) Applied Kalman Filtering (in Japanese). Asakura-Shoten, Tokyo Lehtinen M, Pirjola R (1985) Currents produced in earthed conductor networks by geomagnetically-induced electric fields. Ann Geophys 3(4):479-484

Luther DS, Filloux JH, Chave AD (1991) Low frequency, motionally induced electromagnetic fields in the ocean: 2 electric field and Eulerian current comparison. J Geophys Res 96:12797-12814

Miyazaki K, Sasada M, Yoshioka T (1996) Geological map of Japan 1:50,000 Makabe. Geological Survey of Japan, Tokyo

Molinski TS (2002) Why utilities respect geomagnetically induced currents J Atmos Sol-Terr Phys 64(16):1765-1778

Mori T, Fukui F, Nakajima S, Muromatsu F, Ichiji N, Sasaki I, Harada H, Ishii Y (1978) Resistivity measurement at Kami-Aoyagi, Yasato. Gijyutuhoukoku 18(2):33-43 (in Japanese)

Ookawa T, Nakaya K, Kumasaka N (1995) Research on a long-term stability of measured geoelectric field data. Gijyutuhoukoku 34(3-4):25-29 (in Japanese)

Owada T, Tokumoto T, Yamada Y, Ozima M, Kumasaka N, Yokoyama M, Sugawara M, Koike K, Shimizu Y (1998) Introduction to our new system: magnetometer for wide frequency range. Memo Kakioka Mag Obs 26(2):1-14, in Japanese with English abstract. English Translation is available at http://www.kakiokajma.go.jp/publ/journal_DB/pdf_files/ technical_report_of_KMO_sup_01_01.pdf. Accessed on 29 Octber 2014

Püthe C, Manoj C, Kuvshinov A (2014) Reproducing electric field observations during magnetic storms by means of rigorous 3-D modelling and distortion matrix co-estimation. Earth Planets Space 66(1):1-10

Pulkkinen A, Bernabeu E, Eichner J, Beggan C, Thomson AWP (2012) Generation of 100-year geomagnetically induced current scenarios. Space Weather 10, S04003, Doi: 10.1029/2011SW000750

Rooney WJ (1949) Earth-current results at Tucson Magnetic Observatory, 1932-1942. Res Dep of Terr Magn Carnegie Inst Washington 9:1-307

Schultz A, Larsen JC (1987) On the electrical conductivity of the mid-mantle-l. Calculation of equivalent scalar magnetotelluric response functions. Geophys J R Astron Soc 88:733-761

Schultz A, Kurtz RD, Chave AD, Jones AG (1993) Conductivity discontinuities in the upper mantle beneath a stable craton. Geophys Res Lett 20:2941-2944

Schmucker U (1970) Anomalies of geomagnetic variations in the Southwestern United States. Bull Scripps Inst Oceanogr 13:1-165

Schmucker U (1973) Regional induction studies: A review of methods and results. Phys Earth Planet Inter 7:365-378

The Central Meteorological Observatory of Japan (1951) Annual report of the Kakioka Magnetic Observatory for the year 1935. The Central Meteorological Observatory of. Japan, Tokyo

The Central Meteorological Observatory of Japan (1952) Report of the Kakioka Magnetic Observatory geoelectricity 1936-1940. The Central Meteorological Observatory of. Japan, Tokyo

The Central Meteorological Observatory of Japan (1954) Report of the Kakioka Magnetic Observatory geoelectricity 1941-1945. Japan, The Central Meteorological Observatory of Japan

The Central Meteorological Observatory of Japan (1956) Report of the Kakioka Magnetic Observatory geoelectricity 1946-1950. Japan, The Central Meteorological Observatory of

Viljanen A, Pirjola R, Wik M, Ádám A, Prácser E, Sakharov Y, Katkalov J (2012) Continental scale modelling of geomagnetically induced currents. J Space Weather Space Clim 2:A17, Doi: 10.1051/swsc/2012017

Watari S, Kunitake M, Kitamura K, Hori T, Kikuchi T, Shiokawa K, Nishitani N, Kataoka R, Kamide Y, Aso T, Watanabe Y, Tsuneta Y (2009) Measurements of geomagnetically induced current in a power grid in Hokkaido, Japan. Space Weather 7, S03002, Doi: 10.1029/2008SW000417

Yamazaki A, Mishima T (2013) Frequency characteristics of high-sensitivity fluxgate magnetometers at Kakioka, Kanoya, and Memambetsu Magnetic Observatories. Technical Report of the Kakioka Magnetic Observatory 
10(1):9-16, in Japanese with English abstract. Available at http://www. kakioka-jma.go.jp/publ/journal_DB/pdf_files/technical_report_of_KMO_14_ 02.pdf. Accessed on 29 October 2014

Yanagihara K, Yokouchi T (1965) Local anomaly of earth-current and earth-resistivity. Memo Kakioka Mag Obs 12(1):105-113, in Japanese with English abstract. Available at http://www.kakioka-jma.go.jp/publ/journal_DB/pdf_files/ memoirs_of_KMO_25_06.pdf. Accessed on 23 September 2014 Yokoyama I (1962) Relations between the short period changes in geomagnetism and in telluric currents (continued). J F S Hokkaido Univ Series VII I(6):393-403

Yoshimatsu T (1957) Universal earth-currents and their local characteristics. Memo Kakioka Mag Obs 1(suppl):1-109, Available at http://www.kakioka-jma. go.jp/publ/journal_DB/pdf_files/memoirs_of_KMO_17_01.pdf. Accessed on 23 Sept 2014

\section{Submit your manuscript to a SpringerOpen ${ }^{\circ}$} journal and benefit from:

- Convenient online submission

- Rigorous peer review

- Immediate publication on acceptance

- Open access: articles freely available online

- High visibility within the field

- Retaining the copyright to your article 